\title{
Comparison of three approaches of Bernese periacetabular osteotomy
}

\author{
This article was published in the following Dove Press journal: \\ Therapeutics and Clinical Risk Management \\ 12 January 2016 \\ Number of times this article has been viewed
}

\section{Dianzhong Luo \\ Hong Zhang \\ Weijia Zhang}

Division of Joint Surgery and Sport Medicine, Department of Orthopaedics, First Affiliated Hospital of Chinese PLA General Hospital, Beijing, People's Republic of China
Correspondence: Dianzhong Luo Division of Joint Surgery and Sport Medicine, Department of Orthopaedics, First Affiliated Hospital of Chinese PLA General Hospital, 5I Fucheng Road, Beijing 100048, People's Republic of China

Tel +861066848813

Fax +861068989121

Email dianzhongII@I63.com
Background: Developmental dysplasia of the hip is a common disease and treated with various surgical approaches. Improved ilioinguinal (I-I) approach, two-incision Smith-Peterson (TSP) approach, and modified Smith-Peterson (MSP) approach are three main approaches; however, they are rarely compared. The present study compared the operative time, blood loss, intraoperative and postoperative allogeneic blood transfusion, and postoperative complications of these three different approaches.

Hypothesis: Surgical approach does not influence the operation time, blood loss, and complications of periacetabular osteotomy.

Level of evidence: Level III. Case-control study.

Patients and methods: In a total of 101 hips of 95 cases, from February 2010 to July 2011, three different approaches of Bernese periacetabular osteotomy, I-I, TSP, and MSP, were conducted. The operation time, intraoperative bleeding, allogeneic blood transfusion, and early complications in different operation approaches were compared by a retrospective study when there were similar ages, genders, and lesions.

Results: Among the three approaches, I-I had less operation time and more blood loss $(P<0.05)$, TSP had less blood loss $(P<0.05)$ but more complications, and MSP had less blood loss $(P<0.05)$ and less complications.

Discussion: The MSP approach is superior to the other two approaches in doing periacetabular osteotomy.

Keywords: periacetabular osteotomy, operation approaches, complications

\section{Introduction}

Developmental dysplasia of the hip (DDH) is one of the most common bone dysplasia, and early detection and a proper treatment can yield a good prognosis. The treatment of those patients who have no dislocation of hip claudication and appear symptomatic after puberty is more difficult. In 1984, Ganz et al proposed the treatment of adult hip dysplasia by periacetabular osteotomy, also known as Bern Periacetabular osteotomy. ${ }^{1}$ Owing to the good long-term efficacy, it has been carried out in a number of countries and regions. Because of the depth of the surgical site and abundance of the blood vessels and nerves around the femoral acetabular joint, surgery-related complications are common ${ }^{2,3}$ and technical requirements for surgical operation are higher. In order to reduce complications and improve the accuracy of the surgical technique, different approaches and enhancements are implemented. ${ }^{4-7}$ Surgical approaches roughly included modified Smith-Peterson (MSP) approach, improved ilioinguinal (I-I) approach, and two-incision Smith-Peterson (TSP) approach. ${ }^{8}$ The comparison of different surgical approaches of acetabular osteotomy has not been reported yet. In this paper, I-I, TSP, and MSP were compared based on the operative time, blood loss, intraoperative and postoperative allogeneic blood 
transfusion, and postoperative complications to determine the advantages of three different approaches.

\section{Patients and methods}

\section{Patients}

From February 2010 to July 2011 in our hospital, DDH acetabular osteotomy surgery was applied to $>120$ patients aged from 11 years to 45 years using the I-I, TSP, and MSP approaches, respectively. Some patients simultaneously underwent arthroscopic exploration cleanup and femoral head and neck molding or labrum repair surgery. The three surgical approaches were preliminarily compared and are summarized below. This study was approved by the ethics committee of the First Affiliated Hospital of PLA General Hospital, and all patients signed informed consent for the specimen collection and application in the study.

\section{Inclusion criteria}

Patients with unilateral periacetabular osteotomy with simultaneous proximal femoral derotation osteotomy, hip surgical dislocation exploration, acetabular osteotomy with hip arthroscopic exploratory surgery at the same time, and contralateral hip fracture nail surgery were chosen. Patients with simple proximal femur osteotomy were excluded. There were 95 cases of patients meeting the inclusion criteria with 101 hips: including 14 males with 14 hips and 81 cases of females with 87 hips. There were five females with ten hips with double hip surgery: one case with I-I approach, one case with MSP approach, and three cases with different approaches for the bilateral hip.

\section{Surgical method}

\section{I-I approach}

An arc incision with a length of $18-22 \mathrm{~cm}$ was made from the front of the iliac crest to the pubic bone and $2.0 \mathrm{~cm}$ above the inguinal ligament. The skin, subcutaneous tissue, and the external oblique fascia were cut successively, and the subperiosteal dissection was made close to the inner panel iliac the iliac wall and pubic hair were revealed from the outside window. The vertical line before and after the sheath was cut at the top of the pubic bone and outside the edge of the rectus abdominis. The four sides of the body, the upper ramus of the pubic bone, sneak separation obturator, and the ischial ramus were revealed after extraperitoneal isolation. First, suprapubic ramus osteotomy was carried out, and then acetabular osteotomy at $2.5 \mathrm{~cm}$ above the joint space and osteotomy of the four sides of the body were performed. Finally, osteotomy of the ischial ramus was performed under perspective. After the completion of osteotomy, the acetabular was clamped by the pelvic reset forceps and rotated forward and outward, and the acetabulum apex angle appeared close to $0^{\circ}$ under perspective. The acetabular was mildly anteverted, and the acetabular rotation center was kept unchanged or slightly displaced and fixed with $4.5 \mathrm{~mm}$ pelvic screws (Synthes Inc, the Yu Tong Masson).

\section{MSP approach}

Smith-Peterson incision was made forward and downward from the front of the iliac crest with the length of 15-18 cm; the skin, subcutaneous tissue, and the deep fascia were cut successively. The anterior superior iliac spine was chiseled. The ligamentum inguinale and the starting point of sartorius were pulled together to the inside. The surgeon entered through the lower segment from the fascia lata separation between the tensor and sartorius while protecting the lateral femoral cutaneous nerve. The upper segment was stripped within the periosteum of the ilium. The origin of the rectus femoris was incised and reflected, and the iliac wall as well as the four sides of the body, the upper ramus of the pubic bone, and the hip capsule was revealed. Via the interspace between medial side of the hip capsule and the iliolumbar tendon and neck of femur, and ischial ramus were revealed, and line ischial ramus osteotomy was performed, as well as pubic ramus osteotomy, and acetabular roof osteotomy and the four sides of the body osteotomy. After the completion of osteotomy, the osteotomy block was clamped by the acetabular reset forceps and rotated to a satisfactory position with the acetabulum apex angle close to $0^{\circ}$ under perspective. The acetabulum was mildly anteverted, and the acetabular rotation center was unchanged or slightly displaced and fixed with $4.5 \mathrm{~mm}$ pelvic screws. The sight was then flushed and sutured, and the drainage tube was placed.

\section{TSP approach}

The upper section approach (outside the window) was the same as the SP approach with an incision of length $12 \mathrm{~cm}$. A 10-12 cm vertical incision was made at the midpoint of the inguinal ligament in the lower section approach (the inside of the window). Separation was made deep to the femoral vein, with the hip flexed to reveal the ischial branch from the inside of the iliopsoas, and ischial ramus osteotomy was performed under perspective. On the inside of the window, pubic ramus was revealed, and pubic ramus osteotomy was performed. Afterward, osteotomy of the superior aspect of the acetabulum and four sides of the body was at the outside window. The osteotomy block was clamped by the reset forceps and rotated to a satisfactory position and fixed with AO screws. The region was then flushed and sutured, and the drainage tube was placed. 
Table I Comparison of different operative approaches in the 101 cases of acetabular osteotomy

\begin{tabular}{lllll}
\hline Operative approach & Cases (hips) & $\begin{array}{l}\text { Operative time (min) } \\
\text { mean } \pm \text { SD }\end{array}$ & $\begin{array}{l}\text { Intraoperative blood loss }(\mathbf{m L}) \\
\text { mean } \pm \text { SD }\end{array}$ & $\begin{array}{l}\text { Blood transfusion (mL) } \\
\text { mean } \pm \text { SD }\end{array}$ \\
\hline I-I & 49 & $101 \pm 22^{\mathrm{a}}$ & $1,148 \pm 587^{\mathrm{c}}$ & $1,274 \pm 616^{\mathrm{e}}$ \\
MSP & 19 & $133 \pm 3 \mathrm{I}^{\mathrm{b}}$ & $824 \pm 443^{\mathrm{d}}$ & $984 \pm 465$ \\
TSP & 33 & $127 \pm 33^{\mathrm{b}}$ & $715 \pm 280^{\mathrm{d}}$ & $898 \pm 613^{\mathrm{f}}$ \\
P-value & - & 0.000 & 0.000 & 0.014 \\
F-value & - & 46.484 & 8.723 & 4.436 \\
\hline
\end{tabular}

Note: There are significant differences between ${ }^{\mathrm{a}}$ and ${ }^{\mathrm{b}},{ }^{\mathrm{a}}$ and ${ }^{\mathrm{c}}$, and ${ }^{\mathrm{e}}$ and ${ }^{\mathrm{f}}$ with $\mathrm{P}<0.05$.

Abbreviations: min, minute; SD, standard deviation; I-I, improved ilioinguinal; MSP, modified Smith-Peterson; TSP, two-incision Smith-Peterson.

\section{Observed indicators}

Baseline indicators include age, gender, BMI, preoperative and postoperative lateral center-edge angle, and preoperative and postoperative acetabular index of weight-bearing zone (AC) of patients of three groups with different surgical approaches. Subsequently, operation time, blood loss, blood transfusion, and early postoperative complications of different surgical approaches were compared.

The operation time was obtained from the anesthesia document, and the period from the starting time of surgery to the end of surgery was identified as the operation time. Blood loss was also obtained from the anesthesia document. Since each patient adopted autologous blood transfusion in the surgery, blood loss was calculated automatically from the autologous blood transfusion records. Calculation of allogeneic blood transfusion was as follows: $1 \mathrm{U}$ suspension of red blood cells is equivalent to $150 \mathrm{~mL}$ of whole blood; $100 \mathrm{~mL}$ of plasma was approximately the same amount of allogeneic blood. The total amount of intraoperative and postoperative transfusion of allogeneic blood can be found from the blood transfusion record sheet.

Early postoperative complications can be found in the surgical records and postoperative observation and follow-up.

\section{Statistical methods}

SPSS 17.0 software was used to analyze analysis of variance (ANOVA) of a set of data. The baseline indicators, operation time, blood loss, and allogeneic blood transfusion rates were analyzed statistically and compared between groups. A $P$-value $<0.05$ (two-sided) was taken as threshold of statistical significance. The statistical results are shown in Table 1.

\section{Results \\ Clinical data comparability}

The Pearson chi-square test was used to analyze the proportion of men and women of different groups. Chi-square $=0.7749$, degree of freedom $=2$, and $P$-value $=0.5101$, indicating no difference in the proportion of men and women in the three groups. The one-way ANOVA analysis was used to analyze age, BMI, preoperative and postoperative lateral center-edge angles, and preoperative and postoperative $\mathrm{AC}$ indicators of different groups in Table 2, and $P$-values were all greater than 0.05 , indicating that baseline indicators had no difference in the three groups and the baseline indicators were comparable. The postoperative radiographs for three approaches (Figure 1A-C) showed good recovery of all the patients.

\section{Statistical results}

There are significant differences $(P<0.01)$ in the operation time of the I-I approach group and others. TSP and MSP groups have no significant difference with $P>0.05$. The amount of average bleeding in group II showed a significant

Table 2 Comparison of the base line data in the $10 \mathrm{I}$ cases of acetabular osteotomy

\begin{tabular}{|c|c|c|c|c|c|c|c|c|}
\hline $\begin{array}{l}\text { Operative } \\
\text { approach } \\
\text { statistics }\end{array}$ & $\begin{array}{l}\text { Cases } \\
\text { (hips) }\end{array}$ & $\begin{array}{l}\text { Malel } \\
\text { female }\end{array}$ & $\begin{array}{l}\text { Age (years) } \\
\text { mean } \pm \text { SD }\end{array}$ & $\begin{array}{l}\text { BMI }\left(\mathbf{k g} / \mathrm{m}^{2}\right) \\
\text { mean } \pm \text { SD }\end{array}$ & $\begin{array}{l}\text { Preoperative } \\
\text { LCE }\left(^{\circ}\right) \\
\text { mean } \pm \text { SD }\end{array}$ & $\begin{array}{l}\text { Postoperative } \\
\text { LCE }\left(^{\circ}\right) \\
\text { mean } \pm \text { SD }\end{array}$ & $\begin{array}{l}\text { Preoperative } \\
\text { inclination angle } \\
\text { of the acetabular } \\
\text { roof }\left(^{\circ}\right) \\
\text { mean } \pm \text { SD }\end{array}$ & $\begin{array}{l}\text { Postoperative } \\
\text { inclination angle } \\
\text { of the acetabular } \\
\text { roof }\left({ }^{\circ}\right) \\
\text { mean } \pm \text { SD }\end{array}$ \\
\hline I-I & 49 & $8 / 41$ & $30.16 \pm 7.05$ & $22.66 \pm 3.43$ & $0.629 \pm 10.226^{a}$ & $25.18 \mathrm{I} \pm 7.886^{\mathrm{A}}$ & $26.72 \mathrm{I} \pm 8.8 \mathrm{I} \mathrm{I}^{\mathrm{b}}$ & $4.159 \pm 8.699^{B}$ \\
\hline MSP & 19 & $2 / 17$ & $27.32 \pm 9.19$ & $22.62 \pm 3.10$ & $-3.000 \pm 8.162$ & $23.240 \pm 8.852$ & $27.580 \pm 7.320$ & $3.313 \pm 6.380$ \\
\hline TSP & 33 & $4 / 29$ & $29.58 \pm 7.15$ & $22.19 \pm 3.05$ & $2.603 \pm 12.204^{\mathrm{a}}$ & $24.429 \pm 9.630^{\mathrm{a}}$ & $24.319 \pm 9.105$ & $4.277 \pm 6.94 \mid$ \\
\hline$P$-value & - & 0.7749 & 0.375 & 0.801 & 0.251 & 0.742 & 0.376 & 0.919 \\
\hline$F$-value & - & $0.5101^{\mathrm{c}}$ & 0.990 & 0.223 & 1.402 & 0.300 & 0.988 & 0.840 \\
\hline
\end{tabular}

Note: ${ }^{\mathrm{a}}$ and ${ }^{\mathrm{A}}$ have significant difference with $\mathrm{P}<0.05$, ${ }^{\mathrm{b}}$ and ${ }^{\mathrm{B}}$ have significant difference with $\mathrm{P}<0.0 \mathrm{I}$, and ${ }^{\mathrm{c}}$ is the chi-square value.

Abbreviations: SD, standard deviation; BMI, body mass index; LCE, lateral center-edge angle; I-I, improved ilioinguinal; MSP, modified Smith-Peterson; TSP, two-incision Smith-Peterson. 

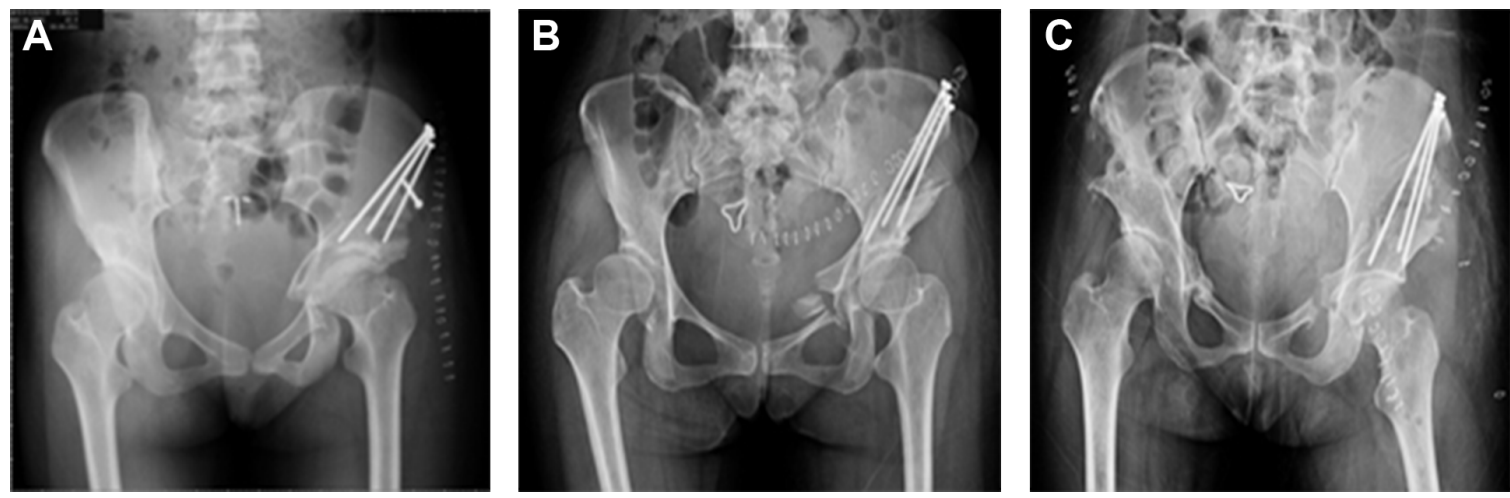

Figure I The AP view (left side) of postoperative radiographs for MSP (A), I-I (B), and TSP (C).

Abbreviations: AP, anteroposterior; I-I, improved ilioinguinal; MSP, modified Smith-Peterson; TSP, two-incision Smith-Peterson.

increase compared to the other two groups with $P<0.05$. TSP and MSP groups have no significant difference $(P>0.05)$. Allogeneic blood transfusion of I-I approach group was higher than that of the TSP group $(P<0.01)$; the MSP group has no significant difference compared with the other two groups with $P>0.05$.

\section{Preoperative complications}

Wound infection

One hip showed deep infection (TSP), two hips showed superficial infection (TSP), and three hips displayed delayed union of skin incision (MSP one case, TSP two cases).

\section{Sciatic nerve irritation}

The I-I approach involved three hips, the TSP approach two hips, and the MSP approach one hip. After 1-6 weeks of neurotrophic therapy, recovery without sequelae was reached.

\section{Lateral femoral cutaneous nerve symptoms}

The I-I approach involved 12 hips, the TSP approach six hips, and the MSP approach three hips.

\section{Corrections}

One hip was renovated immediately after surgery, one hip lost the renovation after 6 months, and one hip was overcorrected and temporary asymptomatic with follow-up.

\section{Fixation screw fracture}

It involved four hips.

\section{Pelvic posterior column fracture}

It involved eight hips. There were three hips with an osteotomy line through the acetabular medial border. No acetabulum or femoral head necrosis was present.

\section{Discussion}

In this group of patients, the patients were more familiar with the pelvic trauma approach; therefore, the I-I approach was adopted in earlier stages. Hereafter, due to surgical trauma and excessive blood loss, the surgery group improved the MSP approach by referencing foreign literature. Only a small part adopted the TSP approach. Since June 2011, after the demonstration in the anatomy, all were converted to the MSP approach. Although the three surgical approaches are effective, statistics showed that there are different advantages and disadvantages of these different approaches.

\section{Operation time}

The operation time of the I-I approach appears to be the shortest with an average of 101 minutes, while that of the MSP approach and TSP approach tends to be a little longer. The possible reason is that the surgery group is skilled in anatomy and performing operation with this approach, while there is a long-learning curve for the MSP approach and TSP approach.

\section{Control of blood loss}

Owing to the computational complexity and the postoperative bleeding with no uniform standards, this paper does not present further research and discussion in this area. In this paper, blood loss is chosen as the reference indicator for different surgery approaches because it is simple to calculate. The amount of blood loss in the I-I approach was more than the other two approaches with an average of $1,148 \mathrm{~mL}$, and there were significant reasons. The acetabular osteotomy blood loss is mainly from several aspects: vasa vasorum of the iliac bone, errhysis of the fracture surface of osteotomy, vasoganglion of the hip basin, vasoganglion of the outside of 
the hip basin, and ramus communicant artery around the hip. The influence of the three approaches on the vasa vasorum of the iliac bone and errhysis of the fractured surface of the osteotomy is similar. The I-I approach goes through the inner side of the pelvis, and poses a risk of tearing the obturator vessels, the femoral vein, and the anastamosis between the inner and outer iliac vessels. Thus, there is a higher incidence of intraoperative vascular injury and significant blood loss. In addition to injury to the vasoganglion of the acetabular inner wall, the MSP approach may only damage small ramus communicant around the joint capsule with fewer intraoperative vascular complications and less blood loss. TSP has little interference on the acetabular vasoganglion, but obviously pulls the femoral artery and vein with a risk of injury.

\section{Nerve damage}

The major nerves around the hip joint include sciatic nerve, femoral nerve, obturator nerve, and lateral femoral cutaneous nerve. Partial injury of the lateral femoral cutaneous nerve is the most common risk in acetabular osteotomy. The MSP approach occasionally damages the first branch of the lateral femoral cutaneous nerve, while there is a higher damage instance of the lateral femoral cutaneous nerve with the other two approaches and a larger area of paresthesia of the lateral femoral skin of dermatome. Since sciatic nerve injury mainly occurred at the osteotomy of the ischial ramus and this part of osteotomy was operated under fluoroscopy, the above three approaches cannot be performed under direct vision because contusions or injury can occur. Sclerites press due to large acetabulum rotation angle and postoperative local hematoma compression of some patients lead to sciatic nerve symptoms, which are usually self-limiting. After sciatic nerve injury, severe pain and discomfort around the hip joint, sciatic nerve numbness, and burning sensation occur, and the symptoms increase with hip flexion. Studies in clinical anatomy found that the distance of the osteotomy line of the ischial ramus, especially the osteotomy line of the lateral cortex, was very close to the static nerve. ${ }^{9}$ Femoral nerve and obturator nerve injuries are rare, and traction injury can be fully restored. Six cases of this group of patients suffered from sciatic nerve irritation and fully recovered after treatment.

\section{Pelvic ring fracture}

When the pelvic ring fractures, it most likely occurs at the osteotomy sight of the ischial ramus; it is caused by an unduly osteotomy under perspective of blinded operation, and most of them can be completely healed after 8-12 weeks.
The osteotomy line enters in the upper corner of the acetabulum, and a thinner acetabular roof occurred in a few cases. Since the articular surface of the weight-bearing area was not involved, the long-term treatment efficacy was not affected after bone healing.

\section{Abnormal correction of the acetabular rotation}

According to the preoperative design, the tilt angle of the acetabular roof and the acetabular anteversion should be corrected to about $0^{\circ}$ and $0^{\circ}-10^{\circ}$, respectively, and the rotation center of the hip joint should be kept unchanged or only slightly displaced. The surgery needs the standard posture and clear perspective, and the weight-bearing area of the acetabular roof and the acetabular edge should be confirmed and internally fixed with accuracy and reliability. Undercorrection is always caused by an incomplete osteotomy of the ischial ramus, irregular osteotomy line, incomplete separation of the acetabulum and the periosteum of the posterior pubis, and the block of the acetabular osteotomy in passive rotation. In the surgery, the flexibility of the acetabular osteotomy block should be confirmed again, the periosteum of the posterior pubis should be monitored especially, and the osteotomy of the ischial ramus should be completed again. Overcorrection was usually caused by too large an anterior cover and the error in the identification of the acetabular front line and the edge in the perspective. The main factors of the corrected loss include a thin acetabular roof and inferior aspect, weak internal fixation, and early postoperative load bearing, resulting in a loss of correction. The acetabular rotation center can be mildly shifted internally and should not be relocated externally in order to avoid big changes in the acetabular rotation center.

The external movement of the acetabular center of rotation can lead to increased local stress, loss of correction, and accelerated joint wear. The relationship between the hip line and the inner edge of the femoral head should be carefully identified, and a parallel bilateral comparison should be done.

\section{Processing of the accompanied abnormal hip joint}

DDH associated with abnormal processing is becoming increasingly important. The preoperative magnetic resonance angiography examination of the hip joint reveals that some cases present a merging acetabular labrum injury, the impact of the junction of the head and neck, acetabular bone cysts, and abnormal anteversion of the femoral neck. In most 
cases, the MSP approach can treat intra-articular lesions simultaneously, while the other two approaches cannot.

\section{Internal fixation}

The MSP approach can accomplish bottom-top fixation of the anterolateral acetabular edge to reach firm fixation and avoid loss of correction. The other two approaches are relatively difficult to fix, and only consequent fixation from the ala of the ilium to the acetabular roof can be performed. In some individual cases, there is loss of correction.

\section{Infection and wound complications}

The incidence rate of wound complications of I-I approach is the lowest, and the TSP has the highest incidence rate of complications. The obvious wound healing scar due to the local tension of the MSP approach will affect visual esthetics for young female patients. The inside incision of the TSP is located inside of the great saphenous vein and the inguinal fossa ovalis and has certain influence on the lymphatic return and the venous return of the inguinal region, medial region of thigh, and perineum, leading to poor healing, subcutaneous hemorrhage, and severe shallow or deep infection. ${ }^{10}$

In conclusion, the MSP approach has the advantages of clear anatomical approach, causing less damage to the blood vessels and nerves, less intraoperative bleeding, and simultaneous processing of the intra-articular lesions. The completion of ilioinguinal approach requires extensive experience due to basin vasoganglion damage, serious intraoperative bleeding, and a high incidence of nerve damage. The TSP approach is close to minimal invasive surgery, although there is a small amount of bleeding. The approach is still needed to be further improved because of incomplete correction and high incidence of complications.

\section{Disclosure}

The authors declare that they have no conflicts of interest in this work.

\section{References}

1. Ganz R, Klaue K, Vinh TS, Mast JW. A new periacetabular osteotomy for the treatment of hip dysplasias: technique and results. Clin Orthop. 1988;232:26-36.

2. Joseph PD, Richard FS. Complications of periacetabular osteotomy. Clin Ortho Relat Res. 1999;363:33-37.

3. Thawrani D, Sucato DJ, Podeszwa DA, DeLaRocha A. Complications associated with the Bernese periacetabular osteotomy for hip dysplasia in adolescents. J Bone Joint Surg Am. 2010;92:1707-1714.

4. Millis MB, Murphy SB, Poss R. Osteotomies about the hip for the prevention and treatment of osteoarthrosis. J Bone Joint Surg Am. 1995;77A: 646-647.

5. Hussell JG, Mast JW, Mayo KA, Howie DW, Ganz R. A comparison of different surgical approaches for the periacetabular osteotomy. Clin Ortho Relat Res. 1999;363:67-72.

6. Bernstein P, Thielemann F, Gunther KP. A modification of periactabular osteotomy using a two-incision approach. J Open Ortho. 2007;1: 13-18.

7. Troelsen A, Elmengaard B, Soballe K. A new minimally invasive transsartorial approach for periacetabular osteotomy. J Bone Joint Surg Am. 2008;90:493-498.

8. Jiang $\mathrm{X}, \mathrm{Xu} \mathrm{H}$. Acetabular osteotomy through Interior-exterior combined approach for the treatment of acetabular dysplasia. Chin J Bone Tumor Bone Dis. 2011;10(5):445-449.

9. Ganz R, Horowitz K, Leunig M. Algorithm for femoral and periacetabular osteotomies in complex hip deformities. Clin Orthop Relat Res. 2010;468:3168-3180.

10. Zhang WJ, Zhang H, Sun DM, et al. 50 cases of the modified S-P approach of the acetabular osteotomy. Chin J Bone Tumor Bone Dis. $2011 ; 10(5): 441-444$.
Therapeutics and Clinical Risk Management

\section{Publish your work in this journal}

Therapeutics and Clinical Risk Management is an international, peerreviewed journal of clinical therapeutics and risk management, focusing on concise rapid reporting of clinical studies in all therapeutic areas, outcomes, safety, and programs for the effective, safe, and sustained use of medicines. This journal is indexed on PubMed Central, CAS,

\section{Dovepress}

EMBase, Scopus and the Elsevier Bibliographic databases. The manuscript management system is completely online and includes a very quick and fair peer-review system, which is all easy to use. Visit $\mathrm{http}: / /$ www.dovepress.com/testimonials.php to read real quotes from published authors. 